\title{
Masked Morphological Priming with Varying Levels of Form Overlap:Evidence from Greek Verbs.
}

Madeleine Voga and Jonathan Grainger

(c) OpenEdition

\section{Journals}

Electronic version

URL: http://journals.openedition.org/cpl/422

DOI: $10.4000 / \mathrm{cpl} .422$

ISSN: $1379-6100$

Publisher

Centre PsyCLÉ

Electronic reference

Madeleine Voga and Jonathan Grainger, « Masked Morphological Priming with Varying Levels of Form Overlap:Evidence from Greek Verbs. », Current psychology letters [Online], 13, Vol. 2, 2004 | 2004, Online since 19 May 2004, connection on 08 September 2020. URL : http://journals.openedition.org/cpl/422 ; DOI : https://doi.org/10.4000/cpl.422

This text was automatically generated on 8 September 2020

(c) All rights reserved 


\title{
160504
}

\section{Masked Morphological Priming with Varying Levels of Form Overlap:Evidence from Greek Verbs.}

\author{
Madeleine Voga and Jonathan Grainger
}

Received January 17, 2004

Revision May 5, 2004

Accepted May 7, 2004

On line May 19, 2004

Introduction

The most common method for examining the role of morphology in word recognition involves priming. Facilitation in processing a target word when it is preceded by a morphologically related prime is taken as evidence that the hypothetical morphemic representation shared by prime and the target has been activated, thereby influencing the process of target recognition. Making this inference, however, is not completely straightforward, because priming between morphologically related words involves the partial repetition of form (orthography and phonology) and meaning, at least for languages such as English, Dutch and German. Until recently, most studies have attempted to separate out effects of morphological priming from semantic and form priming by including semantically related and form-related prime conditions (e.g. Rastle, Davis, Marslen-Wilson, \& Tyler, 2000). According to some authors, morphological priming can be distinguished from the effects of shared meaning and shared form because morphological effects tend to be greater than the sum of orthographic and semantic effects for long SOAs, but this is not the case for short SOAs, where additive effects are found (e.g., Feldman, 2000).

However, relatively few studies have looked at the influence of degree of form overlap in morphologically related prime-target pairs. Yet the question of whether or not degree of form similarity can influence morphological priming is highly relevant to the 
debate on the locus and nature of morphological representations. In its extreme form, this debate opposes a sublexical approach to morphological representation with modality-specific access representations of stems and affixes (e.g., Taft, 1994; Caramazza, Laudanna, \& Romani, 1988; Schreuder \& Baayen, 1995), and a supralexical approach with amodal representations (e.g., Giraudo \& Grainger, 2001; 2003). According to the sublexical approach, when morphological factors do influence word recognition (i.e., excluding cases where recognition operates via whole-word access), then these effects should depend on the level of form overlap across morphologically related words. A complex stimulus must be parsed into its component morphemes by matching the sublexical information extracted from the stimulus (letters, phonemes) with a description of the corresponding morpheme in letters or phonemes (i.e., prelexical morphological decomposition). According to the sublexical account, the size of morphological priming effects should depend on the level of prime-target form overlap.

7 On the other hand, according to the supralexical approach to morphological representation, level of form overlap only indirectly affects morphological processing. Abstract morphemic representations receive activation from whole-word form representations, such that word recognition enables morphological decomposition, and not the contrary. According to the supralexical approach, morphological priming should be obtained even with minimal levels of form overlap across morphologically related pairs.

8 A recent study by Pastizzo and Feldman (2002) examined the influence of form-overlap in morphological priming across past-tense and present-tense forms of regular and irregular verbs. Using the masked priming paradigm with an SOA of $48 \mathrm{~ms}$ these authors found that the magnitude of morphological priming did vary with prime-target form overlap. Not surprisingly, robust priming was observed for regular past-tense forms (hatched-HATCH). Most important though, is that significant facilitation was obtained for irregular forms that had a high degree of overlap with the target (fell - FALL), but not for irregular pairs that shared lower degrees of form relatedness (taught-TEACH). The significant facilitation for irregular high overlap items was only observed when measured against appropriate orthographic control primes (fill-FALL), thus showing the importance of including such controls (Giraudo \& Grainger, 2003; Grainger, Colé \& Segui, 1991). Thus, it may not be regularity that determines whether or not morphological priming can be obtained, but rather the level of form overlap across the morphologically related pairs. In a study using Greek materials, Tsapkini, Jarema and Kehayia (2002) compared priming obtained from regular versus irregular verbs. Verbs were divided into four categories, two regular categories and two irregular categories, following the classification of Ralli (1988), since defining what is a regular or an irregular past-tense form in Greek is not as straightforward as in English. These authors found no difference in performance to the present tense target words from these different categories, and priming effect (past-tense primes compared with unrelated primes) did not interact with morphological category at the short SOA (35ms). Hence, in Greek, regular and irregular past-tense forms appear to be equally efficient primes for the corresponding present-tense targets.

Given the importance of this type of research for determining the nature and locus of morphological representations, the present experiment sought further evidence for influences of form overlap on priming across past and present-tense forms. The use of 
the Greek language in our study allowed us to manipulate degree of form overlap across present and past tense forms of verbs without the confound of regularity. Although Pastizzo and Feldman (2002) demonstrated that high-overlap irregulars do show priming, it remains to be seen whether low-overlap regulars will or will not show priming. According to the sublexical account of morphological representation, variations in form overlap will determine the extent to which a given morphemic representation will be activated during prime and target processing, thus governing the amount of facilitation that is observed. The experiment reported here examines whether morphological priming effects vary as a function of the level of form overlap across the past tense (prime) and present tense (target) form of Greek regular verbs.

MethodParticipants

10 Twenty-seven participants with normal or corrected to normal vision from the University of Montpellier (France), all native speakers of Greek, participated in the experiment.

Stimuli and design

11 Greek offers the opportunity to create two levels of form relatedness for regular verbs, based on the conservation (or not) of the stem between present and past-tense. Past tense formation in Greek can be (roughly) summarized in two types: 1) The stem-final consonant is deleted in the presence of the aspectual marker $-\sigma$ (sigma), for example " $\delta \varepsilon i ́ x v-\omega$ " (I show), where the final omega ( $\omega)$ is the characteristic ending of the $1^{\text {st }} / \mathrm{SG}$ in the present tense, gives " $\varepsilon \delta \varepsilon \xi \xi-\alpha$ " in the past tense: that is the two consonants " $\chi$ " and " $v$ " (chi and ni) have been replaced by the letter " $\xi$ " (ksi), which is the instantiation of the aspectual marker -s. Note that the aspectual marker, can take the form not only of a " $\sigma$ " (sigma), or a " $\xi$ " (ksi), but also " $\psi$ " (psi) or " $\tau \sigma$ " (ts). These forms characterize the past tense without any ambiguity and carry, at least phonologically, the aspectual marker -s (sigma); we used this type of past tense formation to create the materials for the low levels of form overlap between prime and target. 2) The stem is preserved entirely, e.g. the 1 st $/ \mathrm{SG}$ " $\pi \varepsilon \tau \tau^{\alpha}-\omega$ " (I fly) gives “ $\pi \varepsilon \tau_{\tau} \alpha-\xi-\alpha$ ", where the final alpha $(\alpha)$ is the ending of the $1^{\text {st }} / \mathrm{SG}$ in the past tense. The aspectual marker $-\mathrm{s}$ is again instantiated by the "區", but this do not imply any alternation of the stem. That means that in the second type of formation, $100 \%$ of the stem is conserved, whereas in the first type only three of the five letters of the stem are conserved. The high overlap verbs follow this second type of formation.

We selected forty-eight Greek verbs, all regulars, according to Triantafylidis (1941) and forty-eight Greek nonwords. The word targets varied in terms of the level of form relatedness across the present and past-tense forms (see Table 1 for examples and statistics): 1) twenty-four verbs with low form overlap across present and past tense; and 2) twenty-four verbs with high form overlap across present and past tense. Targets were always the $1^{\text {st }} / \mathrm{SG}$ of the present tense form of the verb. Each target was tested in three different priming conditions: (1) an unrelated prime, 2) a past tense prime, and 3) a form-related prime that shared the same number of letters and of phonemes with the target as the past tense primes (see Table 1). The form-related primes had no morphological relation with their corresponding targets. The 48 nonwords were artificial verbs, matched for length and for characteristic endings with real Greek verbs. The nonwords were created to resemble real verbs and respected the phonotactic rules of Greek. The "past tense" primes of the pseudoword targets were constructed in such a way that there were two levels of form overlap between the 
present and the past form as with the word targets : in the low overlap conditions the pseudo-stem-final consonant is deleted, whereas in the high overlap conditions the pseudo-stem is fully conserved. Form-related primes were also created for nonword targets, exactly in the same way as for words. The forty-eight target words and fortyeight nonwords were divided into three lists, each list containing 8 words and 8 nonwords in each condition. The stimuli were rotated within the six conditions in each list using a Latin-square design, so that each word or nonword could appear only once with either an unrelated, a form related or a past tense prime. Participants were randomly assigned to each of the three lists.

Table 1 : Examples of Stimuli Employed in the present study. Phonetic transcripts are provided between antislashes

\begin{tabular}{|c|c|c|c|c|c|c|}
\hline & & \multicolumn{5}{|c|}{ Primes } \\
\hline \multicolumn{2}{|l|}{ Targets } & $\begin{array}{l}\text { Past } \\
\text { tense }\end{array}$ & $\begin{array}{l}\text { Form } \\
\text { related }\end{array}$ & Unrelated & $\begin{array}{l}\text { Form overlap with } \\
\text { past-tense prime }\end{array}$ & $\begin{array}{l}\text { Form overlap with } \\
\text { form related prime }\end{array}$ \\
\hline $\begin{array}{l}\text { low } \\
\text { overlap }\end{array}$ & $\begin{array}{l}\pi \sigma_{i \zeta \zeta} \omega \\
/ \text { pezo/ }\end{array}$ & 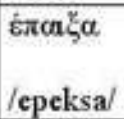 & $\begin{array}{l}\text { đépa } \\
\text { /pera/ }\end{array}$ & $\begin{array}{l}\beta \dot{\alpha} \lambda \omega \omega \\
\text { /valo/ }\end{array}$ & $\begin{array}{l}1-2 \text { phonemes ( } 46 \%) \\
\text { and } 1-3 \text { letters in } \\
\text { common }(48 \%)\end{array}$ & $\begin{array}{l}2 \text { phonemes }(48 \%) \\
\text { and } 1-4 \text { letters in } \\
\text { common }(38 \%)\end{array}$ \\
\hline $\begin{array}{l}\text { high } \\
\text { overlap }\end{array}$ & 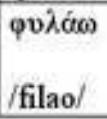 & $\begin{array}{l}\text { } v \dot{\lambda} \alpha_{\zeta}^{k} \alpha \\
\text { /filaksa/ }\end{array}$ & $\begin{array}{l}\varphi \dot{v} \lambda \lambda \alpha \\
/ \text { fila/ }\end{array}$ & $\begin{array}{l}\text { Esopó } \\
\text { /theoro/ }\end{array}$ & $\begin{array}{l}4 \text { phonemes }(74 \%) \\
\text { and } 4 \text { letters in } \\
\text { common }(74 \%)\end{array}$ & $\begin{array}{l}4 \text { phonemes }(74 \%) \\
\text { and } 1.5 \text { letters in } \\
\text { common }(60 \%)\end{array}$ \\
\hline
\end{tabular}

Note: these percentages are calculated on the whole word. Means for form overlap calculated on the stem are as follows: $62 \%$ of letters in common for the low, and $89 \%$ for the high form overlap conditions; and $61 \%$ of phonemes in common for the low, and $89 \%$ for the high form overlap conditions.

\section{Procedure and Apparatus}

13 The experiment was conducted on a PC computer using DMDX software (Forster \& Forster, in press). Each trial consisted of three visual events. The first was a forward mask consisting of a row of nine hash marks that appeared for 500ms. The mask was immediately followed by the prime with an exposure duration of either 33, 50, or $66 \mathrm{~ms}$. The prime was in turn immediately followed by the target word which remained on the screen until participants responded. The inter-trial interval was $500 \mathrm{~ms}$. All stimuli appeared in the middle of the screen presented in Greek lowercase characters in order to preserve the obligatory stress marker over the appropriate vowel. In order to prevent orthographic overlap being confounded with visual overlap, the size of the font was manipulated (Times New Roman 16 point for targets and 12 point for primes). The participants were seated $50 \mathrm{~cm}$ from the computer screen. They were told to make lexical decisions on the target stimuli as quickly and as accurately as possible, by pressing the appropriate key on the computer keyboard. Each participant was randomly assigned to one of the three orders of prime duration tested in three different blocks. After 12 practice trials, participants received the 96 experimental trials of each block with a short break between blocks.

Results

Correct RTs were averaged across participants after excluding outliers (RTs $>1500 \mathrm{~ms}$, $0.1 \%$ of the data). The results are presented in Table 2 . The data were submitted to an analysis of variance with prime type (past tense, unrelated, form-related) and form overlap (high or low) as main factors. The prime duration variable was included in the ANOVA as a within participant factor $(33,50$ or $66 \mathrm{~ms})$ as well as the list variable that was included in order to extract any variance due to counterbalancing across items. 
Table 2 : Raction times (RTs, in Milliseconds) and percentages of errors for Lexical Decisions to Target Words for the 3 Prime Durations in the Form Related, Past Tense, and Unrelated conditions of Experiment 1. Priming effects are calculated by substracting the past tense prime condition from the form related condition (F-M), and from the unrelated condition (U-M)

Words

\begin{tabular}{|c|c|c|c|c|c|c|c|c|c|}
\hline \multirow{2}{*}{$\begin{array}{l}\text { Prime } \\
\text { duration }\end{array}$} & \multirow{2}{*}{ Form overlap } & \multicolumn{2}{|c|}{$\begin{array}{l}\text { Form } \\
\text { related }\end{array}$} & \multicolumn{2}{|c|}{ Past Tense } & \multicolumn{2}{|c|}{ Unrelated } & \multicolumn{2}{|c|}{ Net Priming Effects } \\
\hline & & RT & Error & RT & Error & RT & Error & $F-M$ & $\mathrm{U}-\mathrm{M}$ \\
\hline \multirow[t]{2}{*}{$33 \mathrm{~ms}$} & low & 616 & 6.4 & 617 & 4.1 & 626 & 6.4 & -1 & 9 \\
\hline & high & 586 & 2.3 & 569 & 1.8 & 591 & 0 & 17 & 22 \\
\hline \multirow{2}{*}{$50 \mathrm{~ms}$} & 100 & 635 & 78 & 609 & 37 & 627 & 50 & 26 & 18 \\
\hline & high & 579 & 13 & 552 & 04 & 592 & 23 & 27 & 40 \\
\hline & & & & & & & & & \\
\hline \multirow[t]{2}{*}{$66 \mathrm{~ms}$} & low & 641 & 8.8 & 627 & 4.1 & 644 & 4.6 & 14 & 17 \\
\hline & high & 591 & 1.3 & 569 & 1.3 & 606 & 1.8 & 22 & 37 \\
\hline
\end{tabular}

Nonwords

\begin{tabular}{|c|c|c|c|c|c|c|c|c|c|}
\hline \multirow{2}{*}{$\begin{array}{l}\text { Prime } \\
\text { duration }\end{array}$} & \multirow{2}{*}{ Form overlap } & \multicolumn{2}{|c|}{$\begin{array}{l}\text { Form } \\
\text { related }\end{array}$} & \multicolumn{2}{|c|}{ Past Tense } & \multicolumn{2}{|c|}{ Unrelated } & \multicolumn{2}{|c|}{ Net Priming Effects } \\
\hline & & $\overline{\mathrm{RT}}$ & Error & RT & Error & RT & Error & $\bar{F}-\mathrm{M}$ & $\mathrm{U}-\mathrm{M}$ \\
\hline \multirow[t]{2}{*}{$33 \mathrm{~ms}$} & low & 673 & 4.1 & 670 & 3.7 & 672 & 2.7 & 3 & 2 \\
\hline & high & 680 & 4.1 & 681 & 2.3 & 685 & 5.0 & -1 & 4 \\
\hline \multirow[t]{2}{*}{$50 \mathrm{~ms}$} & low & 665 & 1.8 & 660 & 7.8 & 667 & 2.3 & 5 & 7 \\
\hline & high & 678 & 3.2 & 662 & 4.6 & 680 & 3.7 & 16 & 18 \\
\hline \multirow[t]{2}{*}{$66 \mathrm{~ms}$} & low & 696 & 6 & 677 & 2.7 & 680 & 3.2 & 19 & 3 \\
\hline & high & 690 & 4.1 & 673 & 2.7 & 706 & 2.7 & 17 & 33 \\
\hline
\end{tabular}

15 The main effect of prime type was significant, $F 1(2,144)=23.19, p<.001, F 2(2,92)=4.94$, $p<.01$ as well as the main effect of form overlap, F1 $(1,72)=166.62, p<.001, F 2(1,46)=$ $31.74, p<.001$. The main effect of prime duration was not significant by participants but it was significant by items, $F 1<1, F 2(2,92)=8.67, p<.001$. The overall interaction between prime type and form overlap was not significant $F 1(2,144)=2.77, F 2<1$, and the triple interaction (prime type $\mathrm{x}$ form overlap $\mathrm{x}$ prime duration) was not significant (both Fs $<1$ ).

Planned comparisons examined the effects of morphological primes relative to the unrelated prime condition on the one hand, and the form-related control condition on the other. Past tense primes produced significant facilitation relative to the unrelated condition, $F 1(1,72)=43.08, p<.001, F 2(1,46)=9.01, p<.01$, and the partial interaction (morphological effect $\mathrm{x}$ form overlap) was significant by participants, $F 1(1,72)=6.85$, $p<.05, F 2(1,46)=1.30$. Past tense primes also generated significant facilitation relative to form-related controls, $F 1(1,72)=22.06, p<.001, F 2(1,46)=5.73, p<.05$, and this effect did not interact with degree of form-overlap $F 1(1,72)=1.16, F 2<1$. 

$001, F 2(1,46)=11.25, p<.01$ with participants making more errors in the low form overlap conditions. The effect of prime type was significant by participants $F 1(2,144)=$ $4.75, p<.05, F 2(2,92)=2.52$. Planned comparisons showed that participants made significantly less errors on targets following past tense primes than following formrelated primes, $F 1(1,72)=8.07, p<.001, F 2(1,46)=4.74, p<.05$. main effect of prime duration was significant by items, $F 1<1, F 2(2,92)=11.08, p<.001$, and the main effect of prime type was significant by participants $F 1(2,144)=4.48, p<.05$, $F 2(2,92)=1.77$, as was the main effect of form overlap $F 1(1,72)=4.50, p<.05, F 2<1$. There were no significant interactions. The error analysis for nonwords did not show any significant effects.

Discussion

This experiment demonstrated that when morphological priming is measured relative to an unrelated control condition, priming effects interact with the level of formoverlap across related pairs. Inversely, measuring morphological facilitation against form-related control primes leads to a non-significant interaction. Indeed, at $50 \mathrm{~ms}$ prime exposure, priming effect sizes in RTs were almost identical for the low and highoverlap conditions, and even greater for the low-overlap stimuli in the error rates. The fact that, independently of priming effects, the low-overlap targets generated slower RTs and higher error rates than the high-overlap targets, might reflect some interesting differences in how these two types of word are recognized. However, the main focus of the present study was to compare priming effects for these two types of target word, and it cannot be excluded that uncontrolled variables are the source of this main effect of target type.

The present study examined whether level of form-overlap across present and pasttense forms of regular Greek verbs would influence the amount of priming obtained for such stimuli. The results show that this is the case when morphological priming is measured relative to an unrelated baseline. Greater priming is obtained from verbs that have higher levels of orthographic and phonological overlap across their present and past tense forms. When the form-priming component is neutralized by assessing priming effects relative to a form-related baseline, then morphological priming effects are statistically equivalent for the low and high-overlap stimuli. Thus, the increased morphological facilitation observed relative to unrelated controls is probably due to a summation of morphological priming and form-priming.

21 According to a prelexical decomposition account of morphological parsing, when effects of morphology are observed, then modality-specific sublexical morphemic representations are assumed to be the locus of the effect. Within this framework, we predicted that the size of priming effects obtained across past and present tense forms of a verb should be a function of the similarity of the orthographic realization of the stem in these two forms. High-overlap verbs were predicted to generate more priming than low-overlap verbs. This was not the case in the present study when morphological effects were measured against the appropriate form-related prime condition. These results are compatible with a supralexical account of morphological representation according to which stems and affixes are amodal entities that receive activation from whole-word orthographic and phonological representations during language comprehension. In this theoretical framework, the size of morphological priming 
effects does not depend on the similarity of the physical realisations of a given morpheme in prime and target stimuli.

One result that the supralexical account cannot handle, is the absence of priming for low-overlap irregular verbs in Pastizzo and Feldman's (2002) study. Given the very low level of overlap in these stimuli (e.g., taught-teach), it could be argued that an unsupervised learning mechanism that detects covariation in form and meaning, would not function properly with such extreme cases. The solution adopted in such cases, might then lead to a qualitatively or quantitatively distinct type of representation. This brings us to the on-going, and hotly debated issue of single versus dual-mechanism accounts of processing the past-tense in English (e.g., Pinker \& Ullman, 2002; McClelland \& Patterson, 2002). The present results do not lend support to the type of rule-based processing typically described in dual-route accounts when considering regularly inflected verbs. However, they are also likely to be problematical for single route connectionist models that predict a graded influence of form similarity on morphological processing (Plaut \& Gonnerman, 2000). Further experimentation should help clarify how form similarity determines the types of morphological representation that are developed during language acquisition, and how these subsequently affect skilled reading performance.

Acknowledgements

We are grateful to the staff of the Greek department of Paul Valéry University, Montpellier, France, and especially to the director, Professor Masson, for having arranged the testing of participants in the department.

\section{BIBLIOGRAPHY}

Caramazza, A., Laudanna, A., \& Romani, C. (1988). Lexical access and inflectional morphology.

Cognition, 28, 297-332.

Feldman, L.B. (2000). Are morphological effects distinguishable from the effects of shared meaning and shared form? Journal of experimental psychology: Learning, Memory, and Cognition, 26, 1431-1444.

Forster, K. I., Davis, C., Schoknecht, C., \& Carter, R. (1987). Masked Priming with graphemically related forms: Repetition or partial activation? The Quarterly Journal of experimental Psychology, 39A, 211-251.

Forster, K. I., \& Forster, J. C. (2003). DMDX: A Windows display program with millisecond accuracy. Behavioral Research Methods: Instruments \& Computers, 35, 116-124.

Frost, R., Forster, K. I., \& Deutsch, A. (1997). What can we learn from the morphology of Hebrew: A masked priming investigation of morphological representation. Journal of experimental psychology: Learning, Memory, \& Cognition, 23, 829-856.

Giraudo, H., \& Grainger, J. (2001). Priming complex words: Evidence for supralexical representation of morphology. Psychonomic Bulletin \& Review, 8, 127-131. 
Giraudo, H., \& Grainger, J. (2003). A supralexical model for French derivational morphology. In D., Sandra, \& A. Assink (Eds.) Reading complex words. Amsterdam, Kluwer.

Grainger, J., Colé, P., \& Segui, J. (1991). Masked morphological priming in visual word recognition. Journal of Memory and Language, 30, 370-384.

McClelland, J.L. \& Patterson, K. (2002). Rules or connections in past-tense inflections: What does the evidence rule out? Trends in Cognitive Sciences, 6, 465-472.

Pastizzo, M. J., \& Feldman, L.. B. (2002). Discrepancies between orthographic and unrelated baselines in masked priming undermine a decompositional account of morphological facilitation. Journal of Experimental Psychology: Learning, Memory and Cognition, 28, 244-249.

Pinker, S. \& Ullman, T. (2002). The past and future of the past tense. Trends in Cognitive_Sciences, 6, 456-463.

Plaut, D. C., \& Gonnerman, L. M. (2000). Are non-semantic morphological effects incompatible with a distributed connectionist approach to lexical processing? Language \& Cognitive Processes, 15, 445-485.

Ralli, A. (1988). Eléments de la morphologie du grec moderne: La structure du verbe. Unpublished Ph.D. dissertation, Université de Montréal, Montreal.

Rastle, K., Davis, M. H., Marslen-Wilson, W. D., \& Tyler, L. K. (2000). Morphological and semantic effects in visual word recognition : Atime course study. Language \& Cognitive Processes, 15, 507-537.

Schreuder, R., \& Baayen, R. H. (1995). Modelling morphological processing. In L.B. Feldman (Ed.), Morphological aspects of language processing. (pp. 131-154). Hillsdale, NJ: Erlbaum.

Taft, M. (1994). Interactive activation as a framework for understanding morphological processing. Language \& Cognitive Processes, 9, 271-294.

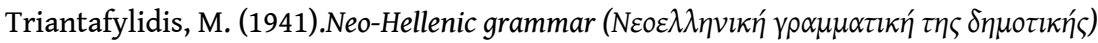

Thessalonique: Aristotle University.

Tsapkini, K., Jarema, G., \& Kehayia, E. (2002). Regularity revisited: Evidence from lexical access of verbs and nouns in Greek. Brain \& Language, 81, 103-109.

\section{ABSTRACTS}

The present study used the masked priming paradigm to examine effects of past tense primes on the recognition of present tense targets in Greek, while varying the level of form-overlap across prime and target. Morphological effects were assessed relative to unrelated as well as formrelated control primes. When measured against unrelated control primes effects of morphological relatedness interacted with level of form overlap. When measured against formrelated controls, morphological priming no longer interacted with level of form overlap. This suggests that masked morphological priming is relatively independent of form relatedness per se, and that abstract, form-independent morphemic representations are at play.

L'étude présentée ici utilise le paradigme de l'amorçage masqué pour examiner l'effet des amorces au passé composé (aoriste) sur la reconnaissance de cibles au présent en grec, en faisant varier le niveau de similarité formelle entre amorce et cible. Les effets morphologiques sont évalués par rapport à une condition de contrôle non reliée, ainsi qu'à une condition de contrôle orthographique. Lorsque les effets sont mesurés par rapport aux contrôles non reliés, l'effet 
morphologique interagit avec le niveau de similarité formelle. Lorsqu'il est évalué par rapport au contrôle orthographique, il n'interagit plus avec la similarité formelle. Ceci suggère que l'amorçage morphologique masqué est relativement indépendant de la similarité formelle per se et que des représentations morphémiques abstraites et indépendantes de la forme sont en jeu.

INDEX

Keywords: morphology, masked priming, Greek, form related control, supralexical model

\section{AUTHORS}

\section{MADELEINE VOGA}

Laboratoire de Psychologie Cognitive, CNRS/Université de Provence

\section{JONATHAN GRAINGER}

Laboratoire de Psychologie Cognitive, CNRS/Université de Provence 29 av. R. Schuman, 13621 Aix-en-Provence, France

grainger@up.univ-mrs.fr 